Article

\title{
Synthesis, Crystal Structure and Hirshfeld Topology Analysis of Polymeric Silver(I) Complex with $s$-Triazine-Type Ligand
}

\author{
Saied M. Soliman 1,2,* and Ayman El-Faham 1,3,* \\ 1 Department of Chemistry, Faculty of Science, Alexandria University, P.O. Box 426 Ibrahimia, \\ 21321 Alexandria, Egypt \\ 2 Department of Chemistry, Rabigh College of Science and Art, King Abdulaziz University, P.O. Box 80200, \\ Jeddah 21589, Saudi Arabia \\ 3 Department of Chemistry, College of Science, King Saud University, P.O. Box 2455, Riyadh 11451, \\ Saudi Arabia \\ * Correspondence: Saied1soliman@yahoo.com (S.M.S.); aymanel_faham@hotmail.com (A.E.-F.); \\ Tel.: +203-591-7883 (S.M.S. \& A.E.-F.); Fax: +203-593-2488 (S.M.S.)
}

Academic Editor: Philip Lightfoot

Received: 16 May 2017; Accepted: 31 May 2017; Published: 2 June 2017

\begin{abstract}
The synthesis, single crystal X-ray diffraction (SC-XRD) characterization and Hirshfeld topology analysis of molecular packing of the coordination polymer $\left[\mathbf{A g}_{2} \mathbf{L}\left(\mathbf{H}_{2} \mathbf{O}\right)_{2}\left(\mathbf{C l O}_{4}\right)_{2}\right]_{n}$, where $\mathbf{L}=2,4,6$-trimorpholino-1,3,5-triazine were discussed. The asymmetric unit comprises one $\mathrm{Ag}_{2} \mathrm{~L}\left(\mathrm{H}_{2} \mathrm{O}\right)_{2}\left(\mathrm{ClO}_{4}\right)_{2}$ unit. The coordination geometries around the two silver atoms are different where $\mathrm{Ag}(1)$ is hexa-coordinated with one $\mathrm{L}$, two bridged water, and two bridged perchlorate augmented with one strong $\mathrm{Ag}-\mathrm{O}$ interaction from the morpholine $\mathrm{O}$-atom of another ligand (L) unit. The coordination environment is more like to a distorted octahedral arrangement according to the criteria of continuous shape measurements. $\operatorname{Ag}(2)$ is coordinated to one $\mathrm{L}$, one terminal water and one terminal perchlorate leading to a distorted trigonal planar arrangement around $\mathrm{Ag}(2)$. Hirshfeld analysis of molecular packing indicated that the most important intermolecular contacts affect the molecular packing of the studied complex are the H...H and the O...H interactions. Atoms in molecules (AIM) and natural bond orbital (NBO) analyses were used to describe the strength and nature of the $\mathrm{Ag}-\mathrm{O}$ and $\mathrm{Ag}-\mathrm{N}$ interactions.
\end{abstract}

Keywords: silver(I); topology; AIM; Hirshfeld; s-triazine

\section{Introduction}

Silver(I) complexes attracted the attention of many research groups due to their fascinating structure aspects as well as their interesting biological activity as antimicrobial and antifungal agents [1-19]. The complexation between the organic ligand and silver(I) is considered an improvement for the ligand biological activity [20]. Silver sulfadiazine [21] is used as an antibacterial topical cream for burn wounds. From structural point of view, the coordination environment of silver is unpredictable and is found surprising for a $\mathrm{d}^{10}$ metal ion. It could accommodate different coordination geometries, such as linear/bent, trigonal planar or tetrahedral which are the most common. Square planar and hexa-coordinated silver(I) complexes are less common in the literature [22]. In addition, it often serves as a connector (L-Ag-L) between ligands leading to fascinating supramolecular structures. The structure topology of the Ag-complexes depends mainly on the nature of the polydentate ligand and anion [23]. Recently, we presented the X-ray structure combined with topology analysis of a huge unit cell comprises of $96\left[\mathrm{AgL}_{2}\right]^{+}$complex ions in 46,000 $\AA^{3}$ unit Cell [24]. Here, we present the synthesis of a new silver(I) perchlorate complex with s-triazine type-ligand namely, 
2,4,6-trimorpholino-1,3,5-triazine (L). The structure aspects of this complex are investigated using single crystal X-ray diffraction (SC-XRD) combined with Hirshfeld and atoms in molecules (AIM) topology analyses.

\section{Results}

The ligand (L, Figure 1) was prepared using the method reported previously in the literature [25]. The studied silver complex has been synthesized using self-assembly technique by mixing the alcoholic solution of the ligand 2,4,6-trimorpholino-1,3,5-triazine (L; Figure 1) with aqueous solution of silver(I) perchlorate in distilled water. The $\left[\mathrm{Ag}_{2} \mathbf{L}\left(\mathrm{H}_{2} \mathrm{O}\right)_{2}\left(\mathrm{ClO}_{4}\right)_{2}\right]_{\mathrm{n}}$ complex is formed as colorless crystals after few days of slow evaporation of the solvent. The structure of the studied silver(I) complex is characterized using elemental analysis, FTIR spectra and SC-XRD analysis.

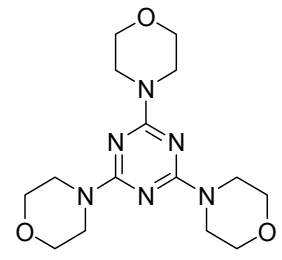

Figure 1. The structure of the ligand $\mathbf{L}$.

\section{Discussion}

\subsection{Crystal Structure Description}

The crystal structure of the $\left[\mathrm{Ag}_{2} \mathbf{L}\left(\mathrm{H}_{2} \mathrm{O}\right)_{2}\left(\mathrm{ClO}_{4}\right)_{2}\right]_{\mathbf{n}}$ complex crystallizes in the centrosymmetric, triclinic space group P-1. The asymmetric unit consists of two silver(I), one 2,4,6-trimorpholino-1,3,5triazine (L) ligand, two coordinated water and two coordinated perchlorate anions. The atomic numbering scheme of the asymmetric unit is shown in Figure 2. Tables S1 and S2 (Supplementary Materials) summarize selected interatomic distances and bond angles, respectively.

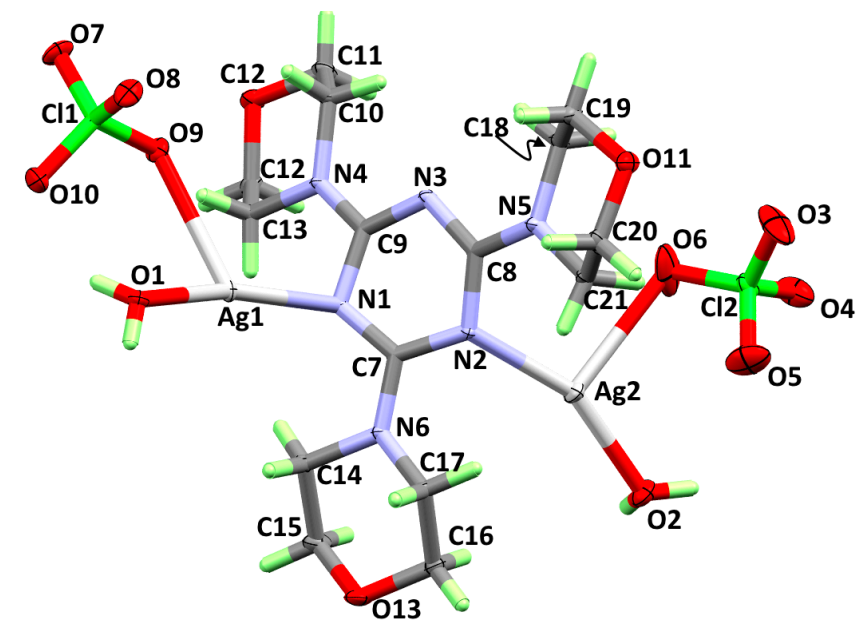

Figure 2. The asymmetric unit and atomic numbering scheme of the $\left[\mathrm{Ag}_{2} \mathbf{L}\left(\mathrm{H}_{2} \mathrm{O}\right)_{2}\left(\mathrm{ClO}_{4}\right)_{2}\right]_{\mathbf{n}}$ complex. Note that the Ag1-N1; 2.325(2), Ag1-O1; 2.346(2) and Ag1-O9; 2.699(2) interatomic distances are longer than the corresponding Ag2-N2; 2.232(2), Ag2-O2; 2.220(2), and Ag2-O6; 2.672(3), respectively.

In the studied silver complex, there are two different silver atoms with different coordination environments. $\mathrm{Ag}(1)$ is hexa-coordinated with one $\mathrm{N}$-atom from the triazine ring $(\mathrm{Ag} 1-\mathrm{N} 1=2.325 \AA)$ of the ligand $(\mathrm{L})$, two water molecules (Ag1-O1 $=2.346$ and $2.685 \AA$ ), two perchlorate units (Ag1-O8 and Ag1-O9 = $2.699 \AA)$ and one O-atom of morpholine (Ag1-O11 = $2.565 \AA$ ) from another ligand 
(L) unit (Figure 3). In this case, two water bridges and two bridged perchlorate units connect two $\operatorname{Ag}(1)$ atoms. The $\operatorname{Ag}(1) \ldots \operatorname{Ag}(1)$ separation is quite large (3.783 $\AA$ ), indicating negligible argentophilic interaction. The $\mathrm{Ag}(1)$ form strong Ag-O interaction ( $2.565 \AA)$ with the O-atom of morpholine from another complex unit leading to the formation of one-dimensional coordination polymer along the $a$-direction (Figure 4). On the other hand, $\operatorname{Ag}(2)$ is coordinated to one $\mathrm{N}$-atom from the triazine ring, one water and one perchlorate anion. In this case, the water and perchlorate anion acti as terminal ligands. The N2-Ag2-O2, N2-Ag2-O6 and O2-Ag2-O6 bond angles are $156.4^{\circ}, 101.7^{\circ}$ and $101.6^{\circ}$, respectively. From this point of view, the $\mathrm{Ag}(2)$ has a distorted trigonal planar geometry (Figure 3 ). It is worth noting that $\mathrm{Ag} 2-\mathrm{O} 6\left(\mathrm{ClO}_{4}\right)$ and $\mathrm{Ag} 2-\mathrm{O} 2\left(\mathrm{H}_{2} \mathrm{O}\right)$ have slightly shorter distances of $2.672 \AA$ and $2.220 \AA$, respectively, than the bridged ones. The structure of studied complex contains numerous hydrogen bonds between the $\mathrm{H}$ atoms of the water molecules with the $\mathrm{O}$-atoms from the perchlorate anion and morpholine ring in the organic ligands (Table 1 and Figure S1; Supplementary Materials). The bridged and terminal water molecules connects the one-dimensional polymer chains via strong

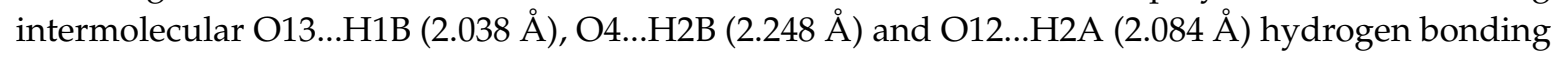
interactions shown in Figure 5.

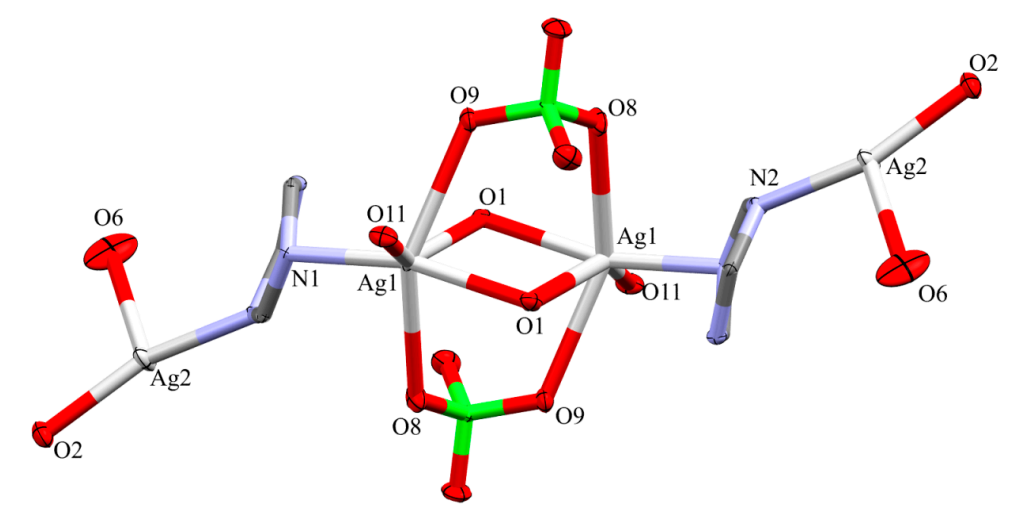

Figure 3. The different coordination environments around Ag-atoms in the studied complex.

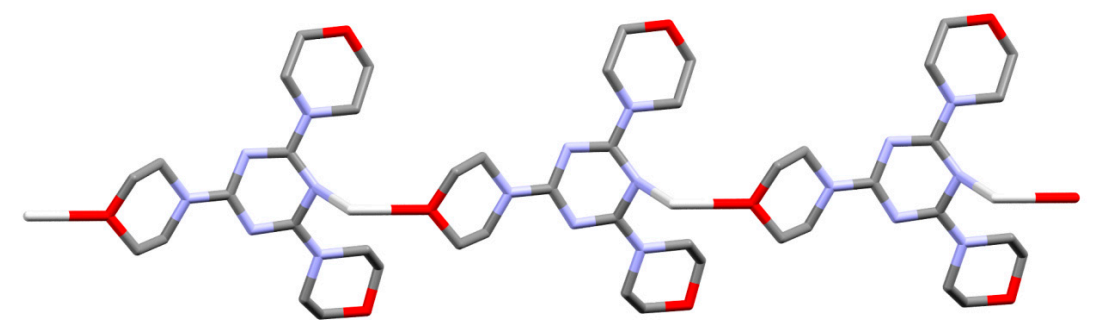

Figure 4. The one-dimensional coordination polymer formed via the Ag1-O11(morpholine) and Ag1-N1(triazine) interactions. Ag1 acts as connector between the ligand units forming 1D coordination polymer.

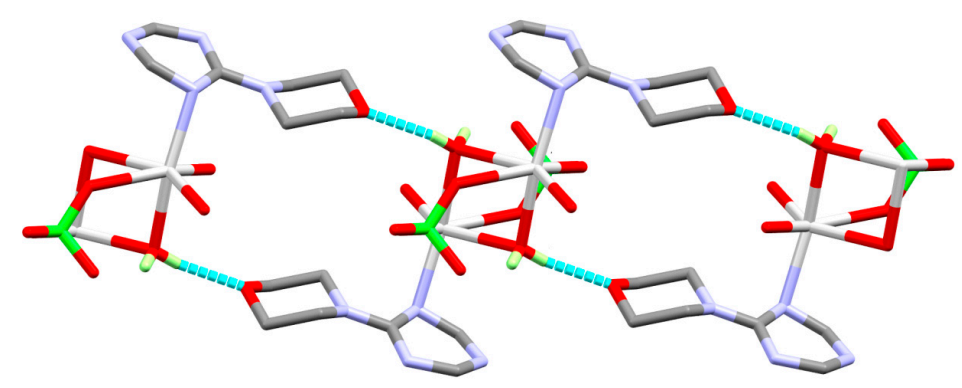

(A)

Figure 5. Cont. 


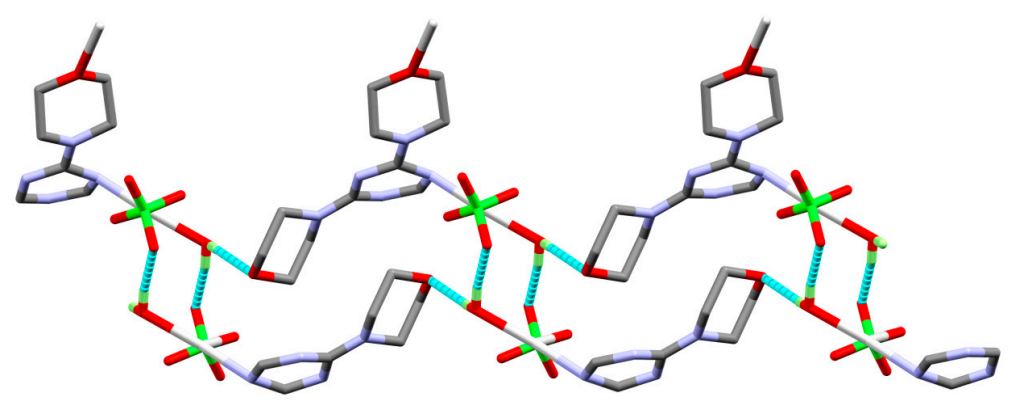

(B)

Figure 5. The hydrogen bonding interactions formed between the morpholine O-atoms and the protons from the bridged (A) and terminal water molecules and perchlorate anion (B) which connects the octahedral and trigonal planar coordination environments, respectively.

Table 1. The important hydrogen bonds in the crystal structure of the studied complex [ $\AA^{\circ}$ and ${ }^{\circ}$.

\begin{tabular}{ccccc}
\hline D-H...A & $\mathbf{d}(\mathbf{D}-\mathbf{H})$ & $\mathbf{d}(\mathbf{H} . . . \mathbf{A})$ & $\mathbf{d}(\mathbf{D} \ldots \mathbf{A})$ & $<$ (DHA) \\
\hline O1-H1A...O10 & 0.80 & 2.17 & 2.870 & 145.4 \\
O1-H1B...O13\#1 & 0.78 & 2.04 & 2.801 & 165.7 \\
O2\#2-H2B\#2...O4\#3 & 0.78 & 2.25 & 2.965 & 152.7 \\
O2\#4-H2A\#4...O12 & 0.85 & 2.08 & 2.893 & 159.9 \\
\hline
\end{tabular}

Symmetry transformations used to generate equivalent atoms: \#1 1-x, -y, 1-z; \#2+x, 1+y, +z; \#3 - x, $1-y$, $2-\mathrm{z} ; \# \mathbf{4} 1+\mathrm{x}, 1+\mathrm{y},+\mathrm{z}$.

\subsection{Continuous Shape Measure (CShM)}

Continuous shape measure (CShM) $[26,27]$ is the most common method used to determine the extent of distortion in a given polyhedral from an ideal shape. There are two possible ligand arrangements around the central metal ion for a hexa-coordinated metal complex: octahedral and trigonal prism. Using the CShM, the values of shape measurements of the coordination environment around $\mathrm{Ag}(1)$ are 4.984 and 9.291 with respect to the ideal octahedron and trigonal prism, respectively. Larger value of shape measurement indicates a more distorted arrangement compared to the ideal case. From this point of view, the geometry around $\mathrm{Ag}(1)$ is more like the octahedron than the trigonal prism.

\subsection{Analysis of Molecular Packing}

The Hirshfeld surfaces mapped over $d_{\text {norm}}$, shape index (SI) and curvedness are shown in Figure 6 and Figure S2 (Supplementary Materials). These properties give information about the intermolecular interactions in the crystal [28-31]. The shape index and curvedness maps are the most suited to identify the $\pi-\pi$ stacking interactions. It is clear from these maps that the packing of the studied complex showed no signs of $\pi-\pi$ stacking interactions as a result of the bulky effect of the morpholine rings attached to the aromatic triazine ring. The curvedness map showed no green flat areas and the shape index has no complementary red (negative) and blue (positive) triangles, which are distinct for the identification of $\pi-\pi$ stacking. The decomposition of the fingerprint plot gave the frequency of each intermolecular interaction occur in the crystal (Figure 7). Based on this data, the zero percent of C...C contacts confirm the absence of any $\pi-\pi$ stacking interactions in the studied system. It is clear that the main intermolecular interactions affecting the molecular packing of the studied complex are the $\mathrm{O} \ldots \mathrm{H}$ and $\mathrm{H} . . . \mathrm{H}$ interactions. The percentages of these interactions are $49.6 \%$ and $38.3 \%$, respectively. Different levels of $\mathrm{H} . . . \mathrm{H}$ contacts were observed among the $\mathrm{C}-\mathrm{H}$ bonds of the morpholine rings. Summary of the most important $\mathrm{H} . . . \mathrm{H}$ interactions are shown in Figure 8. These H...H contacts appeared as red spots in the $\mathrm{d}_{\text {norm }}$ map indicating their significance. The H16B...H19B and H13A...H19A have contact distances of 2.053 and $2.133 \AA$, respectively. The former is significantly shorter than twice the van der Waal radii of $\mathrm{H}$-atom indicating its importance in the molecular packing 
of the studied Ag-complex. The hydrophobic C...H interactions contributed by $2.4 \%$ from the overall fingerprint and appeared as fad red spots in the $d_{\text {norm }}$ map (Figure S3, Supplementary Materials). The C9...H12A interaction have contact distance of $2.653 \AA$, which is also shorter than the van der Waal radii sum of the two elements $(2.79 \AA)$.
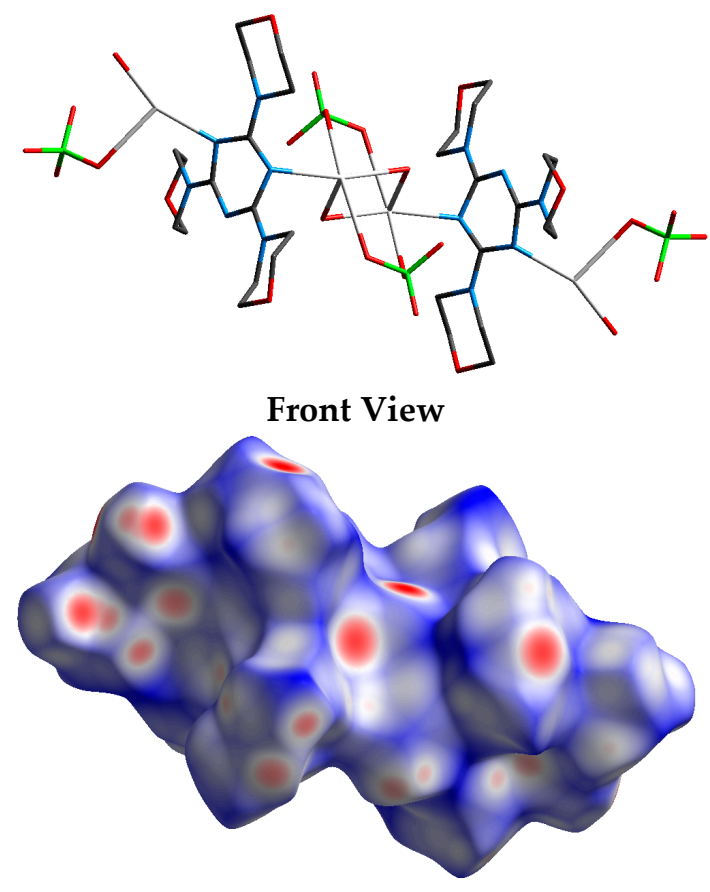

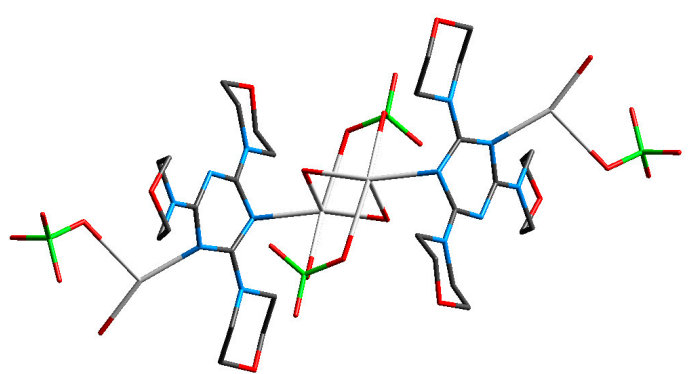

Back View

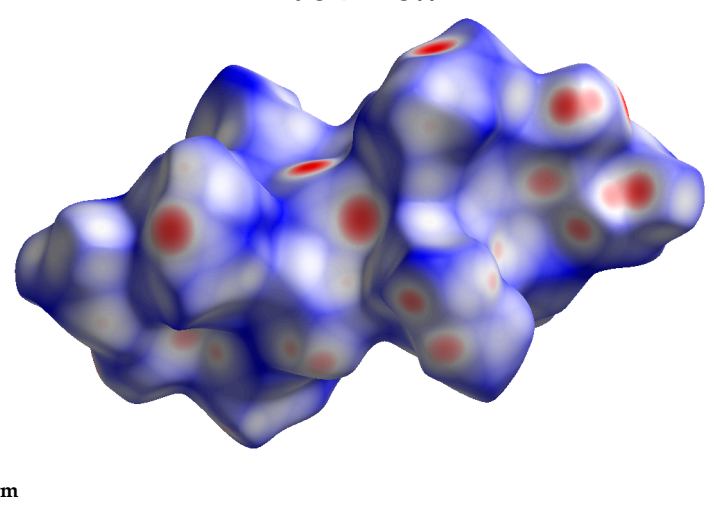

Figure 6. The $d_{\text {norm }}$ Hirshfeld surface of the $\left[\mathrm{Ag}_{2} \mathbf{L}\left(\mathrm{H}_{2} \mathrm{O}\right)_{2}\left(\mathrm{ClO}_{4}\right)_{2}\right]_{n}$ complex.

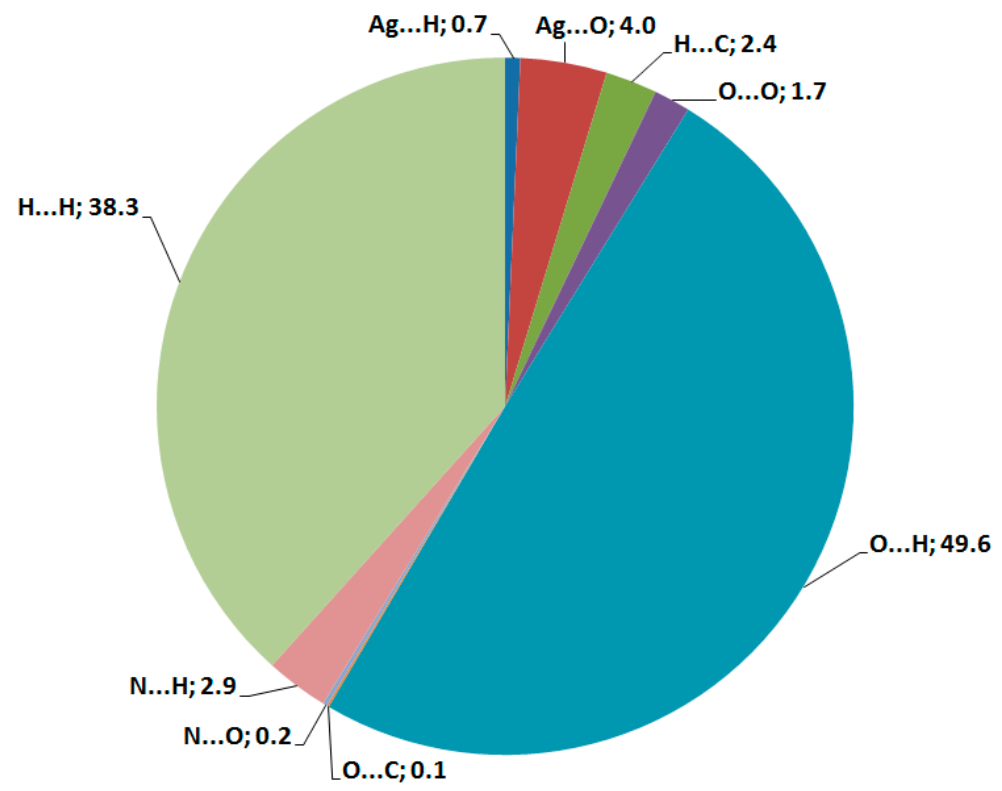

Figure 7. The percentages of all possible intermolecular contacts in the crystal of the studied complex. 


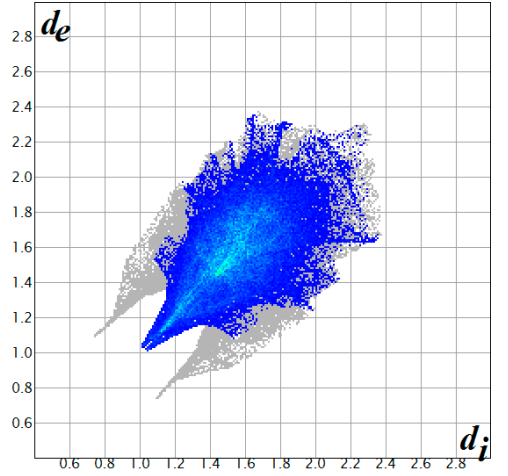

(a)

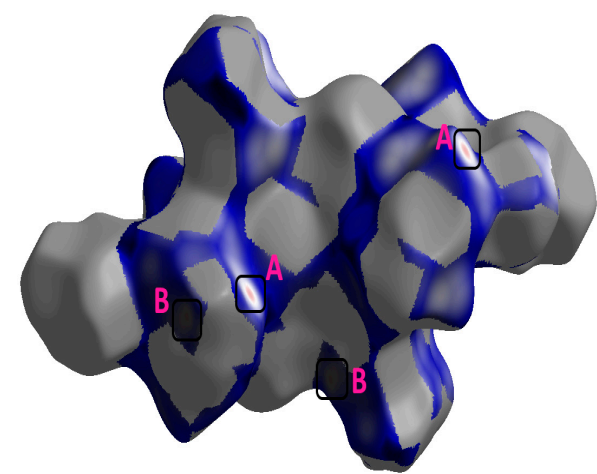

(b)

Figure 8. The decomposed fingerprint plot of the $H$...H contacts (a) and the $d_{\text {norm }}$ map (b) showing the most important H...H intermolecular interactions: (A) H16B...H19B (2.053 Å); and (B) H13A...H19A (2.133 $)$.

On the other hand, the polar O...H interactions occur between the morpholine and perchlorate $\mathrm{O}$-atoms as proton acceptor with either the coordinated water or morpholine rings as proton donor. Of the O...H interactions the shortest contacts are O13...H1B (1.843 $⿱$ A) and O12...H2A (1.954 $\AA$ ) which occur between the protons from the coordinated water molecules and the $\mathrm{O}$-atoms of the neighboring morpholine ring. These $\mathrm{O} . . . \mathrm{H}$ contacts have short intermolecular distances as observed from the intense red spots in the $d_{\text {norm }}$ map and the sharp spikes in the fingerprint plot shown in Figure 9. Moreover, weak polar interaction occurs between the triazine $\mathrm{N}$-atom and the morpholine $\mathrm{C}-\mathrm{H}$ protons with contact distance of $2.660 \AA$ (N3...H12A). This value is slightly longer than the sum of the van der Waal radii of the $\mathrm{N}$ and $\mathrm{H}$ atoms (2.640 $\mathrm{A}$ ). This interaction appeared to be less significant than the $\mathrm{O} . . . \mathrm{H}$ interactions. Interestingly, the decomposed fingerprint plot identified the Ag1...O11 interactions (4.0\%) which appeared as dark red spots in the $\mathrm{d}_{\text {norm }}$ map and sharp spikes in the decomposed FP plot (Figure S4, Supplementary Materials). These results reveal the polymeric nature of the studied complex via the significant Ag1...O11 (2.565 $\mathrm{A}$ ) interactions. On the other hand, two weaker Ag2...O7 and Ag2...O12 interactions were detected with contact distances of $2.996 \AA$ and $2.875 \AA$, respectively. These interactions appeared as fad red spot in the $\mathrm{d}_{\text {norm }}$ map compared to the Ag1...O11 one. The decomposed fingerprint plots shown in Figure S5 (Supplementary Materials) indicated the less importance of the C...O, O...O, $\mathrm{N} . . . \mathrm{O}$ and $\mathrm{Ag} . . . \mathrm{H}$ contacts in the molecular packing of the studied silver complex.

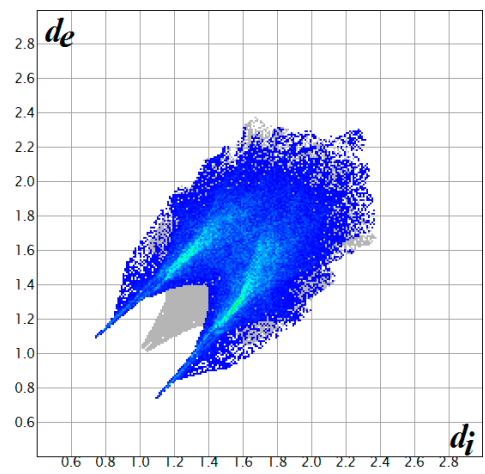

(a)

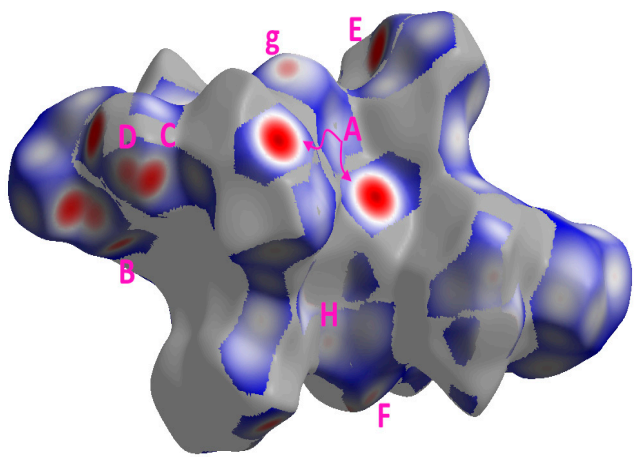

(b)

Figure 9. The decomposed fingerprint plot (a) and the $d_{\text {norm }}$ map (b) of the possible O...H contacts observed from the Hirshfeld surface analysis of the studied silver(I) complex: (A) O13...H1B (1.843 $\AA$ );

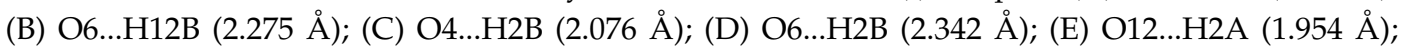

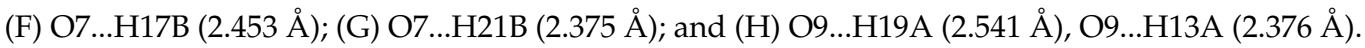




\subsection{AIM and NBO Analyses}

The natural bond orbital (NBO) calculations were employed to discuss the amount of electron density transferred among the ligand and $\mathrm{Ag}(\mathrm{I})$ ion as well as to describe the strength of $\mathrm{Ag}-\mathrm{O}$ and Ag-N interactions. The natural charge at the $\mathrm{Ag}(1)$ is calculated to be $0.5751,0.6140,0.5964$ e using B97D, wB97XD and B3LYP methods, respectively, while for Ag(2) are 0.6255, 0.6961, and $0.6610 \mathrm{e}$, respectively. It is clear that, the more donor atoms around the hexa-coordinated $\mathrm{Ag}(1)$ decrease its positive charge density compared to the tri-coordinated $\operatorname{Ag}(2)$. Hence, the ligands transferred significant amount of electron density in the range of 0.3860-0.4249 e and 0.3039-0.3745 e, respectively, to the Ag-atoms. Moreover, the interaction energies $\left(E^{(2)}\right)$ deduced based on the second order perturbation theory were used to assess the strength of the Ag-O and Ag-N interactions [32-34]. The detailed donor $\left(\mathrm{NBO}_{\mathrm{i}}\right)$-acceptor $\left(\mathrm{NBO}_{\mathrm{j}}\right)$ interactions and their $\mathrm{E}^{(2)}$ values are given in Table $\mathrm{S} 3$ (Supplementary Materials). The net of each of these interactions are summarized in Table 2. The Ag1-N1 (13.29-18.75 kcal/mol) is weaker than the Ag2-N2 (31.48-30.30 kcal/mol) one. Moreover, the Ag1-O1 bonds (12.04-20.36 kcal/mol) of the bridged water are also weaker than the Ag2-O2 $(32.22-40.18 \mathrm{kcal} / \mathrm{mol})$ of the terminal water. The two Ag1-O8 and Ag1-O9 have almost the same interaction energies, which are slightly weaker than the Ag2-O6 of the terminal perchlorate unit. All methods predicted very weak $\mathrm{LP}(\mathrm{Ag} 1) \rightarrow \mathrm{LP}^{*}\left(\mathrm{Ag} 1^{\mathrm{ii}}\right)$, which confirm that the argentophilic interaction among these Ag-atoms are insignificant.

Table 2. Summary of the net intramolecular charge transfer interactions and their $\mathrm{E}^{(2)}$ values $(\mathrm{kcal} / \mathrm{mol})$ included in the Ag-N and Ag-O bonds using different DFT methods.

\begin{tabular}{|c|c|c|c|c|c|c|c|c|c|}
\hline $\mathrm{NBO}_{\mathbf{i}}$ & $\mathrm{NBO}_{\mathbf{j}}$ & B97D & WB97XD & B3LYP & $\mathrm{NBO}_{\mathbf{i}}$ & $\mathrm{NBO}_{\mathrm{j}}$ & B97D & WB97XD & B3LYP \\
\hline LP(N1) & $\mathrm{LP}^{*}(\mathrm{Ag} 1)$ & 13.29 & 18.57 & 14.63 & LP(1)N2 & $\mathrm{LP}^{*}(\mathrm{Ag} 2)$ & 31.48 & 40.30 & 33.75 \\
\hline $\mathrm{LP}(\mathrm{O} 1)$ & $\mathrm{LP}^{*}(\mathrm{Ag} 1)$ & 12.04 & 15.56 & 12.85 & $\mathrm{LP}(\mathrm{O} 2)$ & $\mathrm{LP}^{*}(\mathrm{Ag} 2)$ & 32.22 & 40.18 & 34.08 \\
\hline LP(O1) & $\mathrm{LP}^{*}\left(\operatorname{Ag} 1^{\mathrm{ii}}\right)$ & 15.78 & 20.36 & 17.43 & LP(O6) & $\mathrm{LP}^{*}(\mathrm{Ag} 2)$ & 24.47 & 30.28 & 26.15 \\
\hline LP(O8) & LP*(Ag1) & 23.03 & 29.34 & 25.17 & & & & & \\
\hline LP(O9) & LP*(Ag1) & 22.87 & 29.59 & 24.88 & & & & & \\
\hline LP(O11) & $\mathrm{LP}^{*}(\mathrm{Ag} 1)$ & 16.61 & 22.11 & 18.16 & & & & & \\
\hline LP(Ag1) & LP*(Ag1) & 0.82 & 0.97 & 1.08 & & & & & \\
\hline
\end{tabular}

Moreover, the AIM topological parameters shown in Table S4 (Supplementary Materials) were used to further describe the strength and nature of the Ag-N and Ag-O interactions. The results shown in this table confirmed the stronger Ag2-N2 than Ag1-N1 bond as the former has higher electron density at the corresponding BCP than the latter [35]. Moreover, the interaction energy computed using the relation $\left(E_{\text {int }}=-\mathrm{V}(\mathrm{r}) / 2\right)[36]$ is higher for the Ag2-N2 than that for Ag1-N1, which agrees with the X-ray structure. In addition, it is clear that the Ag2-O2 of the terminal water has higher $\rho(\mathrm{r})$ value than any of the two Ag1-O1 bonds from the bridged water. The same is true for the perchlorate unit where in all cases; shorter distances have higher interactions energies than the longer ones. On the basis of the small negative total energy density $\mathrm{H}(\mathrm{r})$ and the ratio $|\mathrm{V}(\mathrm{r})| / \mathrm{G}(\mathrm{r})$ of $\sim 1$, we concluded that the Ag-N and Ag-O bonds nature are intermediate between the ionic and covalent character $[37,38]$.

\section{Materials and Methods}

\subsection{General}

All chemicals were purchased from commercial sources and were used without further purification. Infrared spectra $\left(4000-400 \mathrm{~cm}^{-1}\right)$ were recorded on Nicolet 6700 spectrometer (International Equipment Trading Ltd., Mundelein, IL, USA) in KBr pellets and the wavenumbers are in $\mathrm{cm}^{-1}$. Elemental analyses were performed on Perkin-Elmer 2400 elemental analyzer (Perkin Elmer, Inc., 940 Winter Street, Waltham, MA, USA). 


\subsection{X-ray Measurements}

Data were collected on a Bruker D8 Quest diffractometer with graphite monochromated Mo-K $\alpha$ radiation, $\lambda=0.71073 \AA$ at 113 (2) $\mathrm{K}$ and a photon detector. Cell refinement and data reduction were carried out using SAINT [39], and a multi-scan absorption correction was made using SADABS [40]. Heavy atom sites were located using direct methods and refined by full-matrix least-squares techniques on F2 including anisotropic displacement parameters for all non-hydrogen atoms using SHELXT [41]. Hydrogen atoms bonded to carbon atoms were refined isotropically using geometrical restraints while the $\mathrm{H}$ atoms bonded to oxygen atoms were allowed to vary freely. The crystallographic data of these complexes were summarized in Table 3. The CIF file CCDC-1549763 contains the supplementary crystallographic data for this compound measured. This can be obtained free of charge from the Cambridge Crystallographic Data Centre via www.ccdc.cam.ac.uk/data_request/cif.

Table 3. Crystallographic data and processing parameters for the studied complex.

\begin{tabular}{|c|c|c|}
\hline Empirical formula & $\mathrm{C}_{15} \mathrm{H}_{28} \mathrm{Ag}_{2} \mathrm{Cl}_{2} \mathrm{~N}_{6} \mathrm{O}_{13}$ & \\
\hline Formula weight & $787.07 \mathrm{~g} / \mathrm{mol}$ & \\
\hline Temperature & $115(2)$ & \\
\hline Wavelength & $0.71073 \AA$ & \\
\hline Crystal system & Triclinic & \\
\hline Space group & $\mathrm{P}-1$ & \\
\hline Unit cell dimensions & $\begin{array}{l}\mathrm{a}=10.0030(15) \AA \\
\mathrm{b}=10.1143(18) \AA \\
\mathrm{c}=13.191(2) \AA\end{array}$ & $\begin{array}{l}\alpha=100.928(5)^{\circ} \\
\beta=92.299(5)^{\circ} \\
\gamma=108.348(5)^{\circ}\end{array}$ \\
\hline Cell volume & $1236.6(4) \AA^{3}$ & \\
\hline Z & 2 & \\
\hline Density (calculated) & $2.114 \mathrm{~g} / \mathrm{cm}^{3}$ & \\
\hline Absorption coefficient & $1.877 \mathrm{~mm}^{-1}$ & \\
\hline $\mathrm{F}(000)$ & 784 & \\
\hline Crystal size (mm) & $0.412 \times 0.211 \times 0.200$ & \\
\hline$\theta$ range for data collection & $2.17^{\circ}$ to $25.31^{\circ}$ & \\
\hline Index ranges & $-11 \leq \mathrm{h} \leq 12,-12 \leq \mathrm{k} \leq 12,-15 \leq 1 \leq 15$ & \\
\hline Reflections collected & 19888 & \\
\hline Independent reflections & $4486[\mathrm{R}(\mathrm{int})=0.0260]$ & \\
\hline Completeness to theta $=25^{\circ}$ & $99.7 \%$ & \\
\hline Refinement method & Full-matrix least-squares on $\mathrm{F}^{2}$ & \\
\hline Data/restraints/parameters & $4486 / 0 / 356$ & \\
\hline Goodness-of-fit on $\mathrm{F}^{2}$ & 1.069 & \\
\hline Final $\mathrm{R}$ indices $[\mathrm{I}>2 \operatorname{sigma}(\mathrm{I})]$ & $\mathrm{R} 1=0.0189, \mathrm{wR} 2=0.0408$ & \\
\hline $\mathrm{R}$ indices (all data) & $\mathrm{R} 1=0.0220, \mathrm{wR} 2=0.0420$ & \\
\hline Extinction coefficient & $0.0062(2)$ & \\
\hline Largest diff. peak and hole & 0.675 and $-0.710 \mathrm{e}^{-3}$ & \\
\hline
\end{tabular}

\subsection{Hirshfeld Surface Analysis}

Hirshfeld surface analyses of the silver complex were made using Crystal Explorer 3.1 program [42]. The Hirshfeld surface, shape index, and curvedness plots were drawn using the same software. The Hirshfeld surfaces mapped over $d_{\text {norm }}$ (range of -0.082 to $1.029 \AA$ ) together with 
their 2D fingerprint plots were used to analyze the intermolecular interactions [43] in the studied complex. The Hirshfeld surfaces mapped over shape index (range of -1.0 to $1.0 \AA$ ) and curvedness ( -4.0 to $4.0 \AA$ ) were drawn to investigate the possibility of $\pi-\pi$ stacking among molecular units.

\subsection{Synthesis of the Silver(I) Complex}

To a solution of $\mathbf{L}$; ( $~ 0.3364 \mathrm{~g}, 1 \mathrm{mmol})$ in $10 \mathrm{~mL}$ methanol, aqueous solution of silver(I) perchlorate $(\sim 0.2073 \mathrm{~g}, 1 \mathrm{mmol})$ was added. The mixture was filtered off and the clear filtrate is left at room temperature for slow evaporation. After 5 days, colorless crystals of $\left[\mathrm{Ag}_{2} \mathbf{L}\left(\mathrm{H}_{2} \mathrm{O}\right)_{2}\left(\mathrm{ClO}_{4}\right)_{2}\right]_{\mathbf{n}}$ complex were obtained. The crystals were collected from solution and were found suitable for $\mathrm{X}$-ray analysis.

Yield: 84\%; IR $\left(v_{\max }, \mathbf{c m}^{-1}\right)$ : [ $\left.\mathbf{A g}_{2} \mathbf{L}\left(\mathbf{H}_{\mathbf{2}} \mathbf{O}\right)_{2}\left(\mathbf{C l O}_{4}\right)_{2}\right]_{\mathbf{n}}: 3422(\mathrm{~m}), 2994(\mathrm{w}), 2970(\mathrm{w}), 2918(\mathrm{w})$, 1541(vs), 1107(vs), 1090(vs), 926(w); Anal. Calcd. $\mathrm{C}_{15} \mathrm{H}_{28} \mathrm{Ag}_{2} \mathrm{Cl}_{2} \mathrm{~N}_{6} \mathrm{O}_{13}: \mathrm{C}, 22.89 ; \mathrm{H}, 3.59 ; \mathrm{N}, 10.68 \%$. Found: C, 22.90; H, 3.60; N, 10.67\%.

\subsection{Computational Details}

Single point calculations for the studied complex were performed using Gaussian 09 program [44]. Different DFT methods (B3LYP, B97D, and WB97XD) were used to describe the nature and strength of the Ag-N and Ag-O interactions in the studied complex. Gaussian built in cc-pvtz basis sets for nonmetal atoms $(\mathrm{C}, \mathrm{H}, \mathrm{N}, \mathrm{O}$ and $\mathrm{Cl})$ and def2-TZVP for silver is used. The latter is obtained from EMSL basis set exchange [45]. The Cartesian coordinates of the input structure are taken from the crystallographic information file (CIF) of the studied silver(I) complex. The resulting wavefunction files were analyzed using Multwfn [46] program to perform the topology analysis in the framework of the quantum theory of atoms in molecules (QTAIM) [47]. Topological parameters such as total electron density $(\rho(r))$, local electron kinetic energy density $(G(r))$, local electron potential energy density $(\mathrm{V}(\mathrm{r}))$ and total energy density $(\mathrm{H}(\mathrm{r}))$ were used to describe the nature of the Ag-N and Ag-O bonds. Moreover, natural bond orbital (NBO) calculations were made using the NBO 3.1 [48] program to assign the nature of orbitals included in the metal-ligand interactions. Using the same method, the natural atomic charges were obtained.

\section{Conclusions}

Using self-assembly technique, the $\left[\mathrm{Ag}_{2} \mathbf{L}\left(\mathrm{H}_{2} \mathrm{O}\right)_{2}\left(\mathrm{ClO}_{4}\right)_{2}\right]_{\text {n }}$ complex was synthesized, where $\mathrm{L}$ is 2,4,6-trimorpholino-1,3,5-triazine. The $\mathrm{X}$-ray crystal structure analysis revealed that, the ligand (L) connects the complex units via strong Ag-O(morpholine) interactions leading to the formation of one-dimensional coordination polymer. The coordination geometry around $\operatorname{Ag}(1)$ and $\operatorname{Ag}(2)$ are distorted octahedral and trigonal planar, respectively. The molecular packing of the studied complex is mainly controlled by the polar O...H and nonpolar H...H interactions. The AIM and NBO results were used to describe the nature and strength of the Ag-O and Ag-N interactions. From the obtained results, it is clear that more donor atoms around the hexa-coordinated $\mathrm{Ag}(1)$ decrease its positive charge density compared to the tri-coordinated $\operatorname{Ag}(2)$. All methods used predicted very weak $\operatorname{LP}(\operatorname{Ag} 1) \rightarrow \mathrm{LP}^{*}\left(\operatorname{Ag} 1^{\mathrm{ii}}\right)$, which confirm that the argentophilic interaction among these Ag-atoms are insignificant. Moreover, the interaction energy computed using the relation $\left(E_{\text {int }}=-V(r) / 2\right)$ is higher for the Ag2-N2 than that for Ag1-N1, which agrees with the X-ray structure.

Supplementary Materials: The following are available online at www.mdpi.com/2073-4352/7/6/160/s1, Figure S1: The hydrogen bonding network along the viewing $b$-direction in the studied silver(I) complex, Figure S2: The shape index (SI) and curvedness Hirshfeld surfaces of the $\left[\mathrm{Ag}_{2} \mathbf{L}\left(\mathbf{H}_{2} \mathbf{O}\right)_{2}\left(\mathbf{C l O}_{4}\right)_{2}\right]_{\mathbf{n}}$ complex, Figure S3: The decomposed fingerprint plot (upper) and $\mathrm{d}_{\text {norm }}$ map (lower) of the C...H interactions, Figure S4: The decomposed FP plot (upper) and the $\mathrm{d}_{\text {norm }}$ map (lower) of the Ag...O interactions: (A) Ag1-O11 (2.565 ̊); (B) Ag2...O12 (2.879 Å); and (C) Ag2...O7 (2.996 ̊). Note the significant variation of the red color intensity, Figure S5: The decomposed fingerprint plot of the less important contacts observed in the crystal of the studied complex, and Figure S6: FTIR spectra of the studied complex. Table S1: Selected Interatomic distances [ $\AA$ ] for studied complex, Table S2: Selected Interatomic angles $\left[{ }^{\circ}\right]$ for studied complex, Table S3: The detailed intramolecular charge transfer 
interactions included in the Ag-N and Ag-O interactions using different DFT methods and Table S4: The AIM topological parameters calculated using different DFT methods.

Acknowledgments: The authors extend their appreciation to the Deanship of Scientific Research at King Saud University for funding this work through research group No (RGP-234, Saudi Arabia).

Author Contributions: Saied M Soliman conceived, designed and performed the synthesis of the studied complex. In addition, he carried out the SC-XRD data collection, wrote the X-ray structure studies and performed the computational studies. Ayman El-Faham carried out the synthesis of the organic ligand and contributed reagents, materials, and analysis tools. Both authors contributed to the preparation of the manuscript.

Conflicts of Interest: The authors declare no conflict of interest.

\section{References}

1. Jaros, S.W.; da Silva, M.F.C.G.; Król, J.; Oliveira, M.C.; Smoleński, P.; Pombeiro, A.J.L.; Kirillov, A.M. Bioactive Silver-Organic Networks Assembled from 1,3,5-Triaza-7-phosphaadamantane and Flexible Cyclohexanecarboxylate Blocks. Inorg. Chem. 2016, 55, 1486-1496. [CrossRef] [PubMed]

2. Jaros, S.W.; da Silva, M.F.C.G.; Florek, M.; Smoleński, P.; Pombeiro, A.J.L.; Kirillov, A.M. Silver(I) 1,3,5-Triaza-7-phosphaadamantane Coordination Polymers Driven by Substituted Glutarate and Malonate Building Blocks: Self-Assembly Synthesis, Structural Features, and Antimicrobial Properties. Inorg. Chem. 2016, 55, 5886-5894. [CrossRef] [PubMed]

3. Smoleński, P.; Jaros, S.W.; Pettinari, C.; Lupidi, G.; Quassinti, L.; Bramucci, M.; Vitali, L.A.; Petrelli, D.; Kochel, A.; Kirillov, A.M. New water-soluble polypyridine silver(I) derivatives of 1,3,5-triaza-7-phosphaadamantane (PTA) with significant antimicrobial and antiproliferative activities. Dalton Trans. 2013, 42, 6572-6581. [CrossRef] [PubMed]

4. Kirillov, A.M.; Wieczorek, S.W.; Lis, A.; da Silva, M.F.C.G.; Florek, M.; Król, J.; Staroniewicz, Z.; Smoleński, P.; Pombeiro, A.J.L. 1,3,5-Triaza-7-phosphaadamantane-7-oxide (PTA=O): New Diamondoid Building Block for Design of Three-Dimensional Metal-Organic Frameworks. Cryst. Growth Des. 2011, 11, 2711-2716. [CrossRef]

5. Jaros, S.W.; da Silva, M.F.C.G.; Florek, M.; Oliveira, M.C.; Smoleński, P.; Pombeiro, A.J.L.; Kirillov, A.M. Aliphatic Dicarboxylate Directed Assembly of Silver(I) 1,3,5-Triaza-7-phosphaadamantane Coordination Networks: Topological Versatility and Antimicrobial Activity. Cryst. Growth Des. 2014, 14, 5408-5417. [CrossRef]

6. Jaros, S.W.; Smoleński, P.; da Silva, M.F.C.G.; Florek, M.; Król, J.; Staroniewicz, Z.; Pombeiro, A.J.L.; Kirillov, A.M. New silver BioMOFs driven by 1,3,5-triaza-7-phosphaadamantane-7-sulfide (PTA=S): Synthesis, topological analysis and antimicrobial activity. CrystEngComm 2013, 15, 8060-8064. [CrossRef]

7. Rowan, R.; Tallon, T.; Sheahan, A.M.; Curran, R.; McCann, M.; Kavanagh, K.; Devereux, M.; McKee, V. 'Silver bullets' in antimicrobial chemotherapy: Synthesis, characterisation and biological screening of some new Ag(I)-containing imidazole complexes. Polyhedron 2006, 25, 1771-1778. [CrossRef]

8. Klasen, H.J. Historical review of the use of silver in the treatment of burns. I. Early uses. Burns 2000, 26, 117-130. [CrossRef]

9. Abu-Youssef, M.A.M.; Langer, V.; Öhrström, L. Synthesis, a case of isostructural packing, and antimicrobial activity of silver(I)quinoxaline nitrate, silver(I)(2,5-dimethylpyrazine) nitrate and two related silver aminopyridine compounds. Dalton Trans. 2006, 21, 2542-2550. [CrossRef] [PubMed]

10. Abu-Youssef, M.A.M.; Langer, V.; Öhrström, L. A unique example of a high symmetry three- and four-connected hydrogen bonded 3D-network. Chem. Commun. 2006, 1082-1084. [CrossRef] [PubMed]

11. Abu-Youssef, M.A.M.; Dey, R.; Gohar, Y.; Massoud, A.A.; Öhrström, L.; Langer, V. Synthesis and Structure of Silver Complexes with Nicotinate-Type Ligands Having Antibacterial Activities against Clinically Isolated Antibiotic Resistant Pathogens. Inorg. Chem. 2007, 46, 5893-5903. [CrossRef] [PubMed]

12. Massoud, A.A.; Langer, V. Bis(1,3,5-triazine-2,4,6-triamine- $\left.\mathrm{kN}^{1}\right)$ silver(I) nitrate. Acta Cryst. 2009, C65, m198-m200. [CrossRef] [PubMed]

13. Najafpour, M.M.; Hołyńska, M.; Amini, M.; Kazemi, S.H.; Lis, T.; Bagherzadeh, M. Two new silver(I) complexes with 2,4,6-tris(2-pyridyl)-1,3,5-triazine (tptz): Preparation, characterization, crystal structure and alcohol oxidation activity in the presence of oxone. Polyhedron 2010, 29, 2837-2843. [CrossRef] 
14. Bosch, E. One- and Two-Dimensional Silver-Coordination Networks Containing $\pi$-Sandwiched Silver-Silver Interactions. Inorg. Chem. 2002, 41, 2543-2547. [CrossRef] [PubMed]

15. Munakata, M.; Wen, M.; Suenaga, Y.; Sowa, T.K.; Maekawa, M.; Anahata, M. Silver(I) complexes of triazine derivatives having stepped $\pi-\pi$ interactions and $2 D$ sheets. Polyhedron 2001, 20, 2037-2043. [CrossRef]

16. Abu-Youssef, M.A.M.; Soliman, S.M.; Langer, V.; Gohar, Y.M.; Hasanen, A.A.; Makhyoun, M.A.; Zaky, A.H.; Öhrström, L.R. Synthesis, Crystal Structure, Quantum Chemical Calculations, DNA Interactions, and Antimicrobial Activity of [Ag(2-amino-3-methylpyridine) $\left.{ }_{2}\right] \mathrm{NO}_{3}$ and [Ag(pyridine-2-carboxaldoxime) $\left.\mathrm{NO}_{3}\right]$. Inorg. Chem. 2010, 49, 9788-9797. [CrossRef] [PubMed]

17. Massoud, A.A.; Gohar, Y.M.; Langer, V.; Lincoln, P.; Svensson, F.R.; Janis, J.; Gårdebjer, S.T.; Haukka, M.; Jonsson, F.; Aneheim, E.; et al. Bis 4,5-diazafluoren-9-one silver(I) nitrate: Synthesis, X-ray structures, solution chemistry, hydrogel loading, DNA coupling and anti-bacterial screening. New J. Chem. 2011, 35, 640-648. [CrossRef]

18. Massoud, A.A.; Langer, V.; Abu-Youssef, M.A.M.; Öhrström, L. The coordination polymer poly $\left[\left(\mu_{3-3}\right.\right.$-aminocarbonylpyrazine-2-carboxylato- $\left.\left.\mathrm{K}^{3} \mathrm{~N}^{1}: \mathrm{O}^{2}: \mathrm{O}^{2 \prime}\right) \operatorname{silver}(\mathrm{I})\right]$. Acta Cryst. 2011, C67, m1-m4. [CrossRef] [PubMed]

19. Massoud, A.A.; Langer, V.; Gohar, Y.M.; Abu-Youssef, M.A.M.; Jänis, J.; Öhrström, L. 2D Bipyrimidine silver(I) nitrate: Synthesis, $\mathrm{X}$-ray structure, solution chemistry and anti-microbial activity. Inorg. Chem. Commun. 2011, 14, 550-553. [CrossRef]

20. Guney, E.; Yilmaz, V.T.; Buyukgungor, O. A three-dimensional silver(I) coordination polymer involving a new bridging mode of saccharinate. Inorg. Chem. Commun. 2010, 13, 563-567. [CrossRef]

21. Klasen, H.J. A historical review of the use of silver in the treatment of burns. II. Renewed interest for silver. Burns 2000, 26, 131-138. [CrossRef]

22. Soliman, S.M.; Mabkhot, Y.N.; Barakat, A.; Ghabbour, H.A. A highly distorted hexacoordinated silver(I) complex: Synthesis, crystal structure, and DFT studies. J. Coord. Chem. 2017, 70, 1339-1356. [CrossRef]

23. Bu, W.-M.; Ye, L.; Fan, Y.-G. Exposure-related health effects of silver and silver compounds: A review. Inorg. Chem. Commun. 2000, 3, 194-197.

24. Abu-Youssef, M.A.M.; Soliman, S.M.; Sharaf, M.M.; Albering, J.H.; Öhrström, L. Topology analysis reveals supramolecular organisation of 96 large complex ions into one geometrical object. CrystEngComm 2016, 18, 1883-1886. [CrossRef]

25. Azarifar, D.; Zolfigol, M.A.; Forghaniha, A.A. A convenient method for the preparation of some new derivatives of 1,3,5-s-triazine under solvent free condition. Heterocycles 2004, 63, 1897-1901. [CrossRef]

26. Ok, K.M.; Halasyamani, P.S.; Casanova, D.; Llunell, M.; Alvarez, S. Distortions in Octahedrally Coordinated $\mathrm{d}^{\circ}$ Transition Metal Oxides: A Continuous Symmetry Measures Approach. Chem. Mater. 2006, 18, 3176-3183. [CrossRef]

27. Santiaqo, A.; David, A.; Llunell, M.; Pinsky, M. Continuous symmetry maps and shape classification. The case of six-coordinated metal compounds. New J. Chem. 2002, 26, 996-1009.

28. Spackman, M.A.; McKinnon, J.J. Fingerprinting intermolecular interactions in molecular crystals. CrystEngComm 2002, 4, 378-392. [CrossRef]

29. McKinnon, J.J.; Jayatilaka, D.; Spackman, M.A. Towards quantitative analysis of intermolecular interactions with Hirshfeld surfaces. Chem. Commun. 2007, 3814-3816. [CrossRef]

30. Spackman, M.A.; Jayatilaka, D. Hirshfeld surface analysis. CrystEngComm 2009, 11, 19-32. [CrossRef]

31. Hirshfeld, F.L. Bonded-atom fragments for describing molecular charge densities. Theor. Chim. Acta 1977, 44, 129-133. [CrossRef]

32. Foster, J.P.; Weinhold, F. Natural hybrid orbitals. J. Am. Chem. Soc. 1980, 102, 7211-7218. [CrossRef]

33. Reed, A.E.; Weinstock, R.B.; Weinhold, F. Natural population analysis. J. Chem. Phys. 1985, 83, 735-746. [CrossRef]

34. Reed, A.E.; Curtiss, L.A.; Weinhold, F. Intermolecular interactions from a natural bond orbital, donor-acceptor viewpoint. Chem. Rev. 1988, 88, 899-926. [CrossRef]

35. Bader, R.F.W.; Essen, H. The characterization of atomic interactions. J. Chem. Phys. 1984, 80, $1943-1960$. [CrossRef]

36. Espinosa, E.; Molins, E.; Lecomte, C. Hydrogen bond strengths revealed by topological analyses of experimentally observed electron densities. Chem. Phys. Lett. 1998, 285, 170-173. [CrossRef] 
37. Espinosa, E.; Alkorta, I.; Elguero, J.; Molins, E. From weak to strong interactions: A comprehensive analysis of the topological and energetic properties of the electron density distribution involving X-H...F-Y systems. J. Chem. Phys. 2002, 117, 5529-5542. [CrossRef]

38. Cremer, D.; Kraka, E. A description of the chemical-bond in terms of local properties of electrondensity and energy. Croat. Chem. Acta 1984, 57, 1259-1281.

39. SAINT, Version 4, Version 4 ed.; Siemens Analytical X-ray Instruments Inc.: Madison, WI, USA, 1995.

40. Sheldrick, G.M. SADABS; University of Goettingen: Goettingen, Germany, 1996.

41. Sheldrick, G.M. SHELXT_-Integrated space-group and crystal-structure determination. Acta Cryst. 2015, A71, 3-8. [CrossRef] [PubMed]

42. Wolff, S.K.; Grimwood, D.J.; McKinnon, J.J.; Turner, M.J.; Jayatilaka, D.; Spackman, M.A. Crystal Explorer, Version 3.1; University of Western Australia: Perth, Australia, 2012.

43. Mudsainiyan, R.K.; Jassal, A.K.; Arora, M.; Chawla, S.K. Synthesis, crystal structure determination of two-dimensional supramolecular coordination polymer of silver(I) with 1,2-Bis(phenylthio)ethane and its Hirshfeld surface analysis. J. Chem. Sci. 2015, 127, 849-856. [CrossRef]

44. Frisch, M.J.; Trucks, G.W.; Schlegel, H.B.; Scuseria, G.E.; Robb, M.A.; Cheeseman, J.R.; Scalmani, G.; Barone, V.; Mennucci, B.; Petersson, G.A.; et al. Gaussian 09, Revision D.01; Gaussian, Inc.: Wallingford, CT, USA, 2009.

45. Schuchardt, K.L.; Didier, B.T.; Elsethagen, T.; Sun, L.; Gurumoorthi, V.; Chase, J.; Li, J.; Windus, T.L. Basis Set Exchange: A Community Database for Computational Sciences. J. Chem. Inf. Model. 2007, 47, 1045-1052. [CrossRef] [PubMed]

46. Lu, T.; Chen, F. Multiwfn: A multifunctional wavefunction analyzer. J. Comput. Chem. 2012, 33, 580-592. [CrossRef] [PubMed]

47. Bader, R.F.W. Atoms in Molecules: A Quantum Theory; Oxford University Press: Oxford, UK, 1990.

48. Glendening, E.D.; Reed, A.E.; Carpenter, J.E.; Weinhold, F. NBO Version 3.1, CI; University of Wisconsin: Madison, WI, USA, 1998.

(C) 2017 by the authors. Licensee MDPI, Basel, Switzerland. This article is an open access article distributed under the terms and conditions of the Creative Commons Attribution (CC BY) license (http:// creativecommons.org/licenses/by/4.0/). 